\title{
Cannabis in medicine: a national educational needs assessment among Canadian physicians
}

\author{
Daniel Ziemianski ${ }^{1}$, Rielle Capler ${ }^{2}$, Rory Tekanoff ${ }^{5}$, Anaïs Lacasse ${ }^{3}$, Francesca Luconi ${ }^{4}$ and Mark A Ware ${ }^{1 *}$
}

\begin{abstract}
Background: There is increasing global awareness and interest in the use of cannabis for therapeutic purposes (CTP). It is clear that health care professionals need to be involved in these decisions, but often lack the education needed to engage in informed discussions with patients. This study was conducted to determine the educational needs of Canadian physicians regarding CTP.

Methods: A national needs assessment survey was developed based on previous survey tools. The survey was approved by the Research Ethics Board of the McGill University Health Centre Research Institute and was provided online using LimeSurvey ${ }^{\oplus}$. Several national physician organizations and medical education organizations informed their members of the survey. The target audience was Canadian physicians. We sought to identify and rank using 5-point Likert scales the most common factors involved in decision making about using CTP in the following categories: knowledge, experience, attitudes, and barriers. Preferred educational approaches and physician demographics were collected. Gap analysis was conducted to determine the magnitude and importance of differences between perceived and desired knowledge on all decision factors.
\end{abstract}

Results: Four hundred and twenty six responses were received, and physician responses were distributed across Canada consistent with national physician distribution. The most desired knowledge concerned "potential risks of using CTP" and "safety, warning signs and precautions for patients using CTP". The largest gap between perceived current and desired knowledge levels was "dosing" and "the development of treatment plans".

Conclusions: We have identified several key educational needs among Canadian physicians regarding CTP. These data can be used to develop resources and educational programs to support clinicians in this area, as well as to guide further research to inform these gaps.

Keywords: Cannabis, Medical marijuana, Needs assessment, Continuing medical education, Health professionals

\section{Background}

Canadian patients have had access to cannabis for therapeutic purposes (CTP) under Health Canada's Medical Marihuana Access Program (MMAP) since 1999. As of June 2013, over 30000 Canadians had licenses to possess CTP; this was projected to reach approximately 50 000 in 2014 and 400000 in 2024 [1]. The new Marihuana for Medical Purposes Regulations (MMPR), which came into effect on 19 June 2013, completely replaced the Medical Marihuana Access Regulations (MMAR) on April

\footnotetext{
* Correspondence: mark.ware@mcgill.ca

${ }^{1}$ Alan Edwards Pain Management Unit, McGill University Health Center Research Institute; Canadian Consortium for the Investigation of Cannabinoids, A5.140 Montreal General Hospital, 1650 Cedar Avenue, Montreal, Quebec H3G 1A4, Canada

Full list of author information is available at the end of the article
}

12014 [2]. Under the MMPR, patients may be authorised to possess herbal cannabis if they are issued a valid medical document from either a physician or a nurse practitioner; the medical document is not strictly speaking a 'prescription' as cannabis is not an approved drug, but it does contain information on daily 'dose' of cannabis (in grams/day) and duration of validity. No diagnosis is required as there is no formal 'indication' for CTP. The MMPR therefore maintains the physician's pivotal role in patients' access to CTP, despite concerns expressed by physicians about insufficient information on the risks and benefits of CTP, insufficient information regarding the appropriate use of CTP [3,4] and insufficient information with which to compare CTP with pharmaceutical cannabinoids. 
Prior physician surveys have explored opinions about cannabis legalization [5-8] and attitudes towards CTP $[9,10]$. CTP-related surveys have been directed at specific physician populations, including oncologists [6-8] or family physicians [9]. The need for further medical education and training on CTP has been reported by Colorado family physicians [9] and American oncologists [6]. An understanding of the current and desired status of Canadian physicians' educational needs on CTP remains to be quantified. We therefore conducted an educational needs assessment among Canadian physicians to quantify perceived knowledge levels and identify knowledge and practice gaps. This survey was also designed to explore Canadian physicians' experiences and attitudes towards CTP, to list perceived barriers to the use of cannabis as a possible treatment option in clinical practice, and to make recommendations for the preferred format of physician education on CTP. The study was conducted in order to inform strategies to overcome knowledge and practice gaps, to increase competence and to improve patient care in this complex and controversial area.

\section{Methods}

We conducted an online survey of Canadian physicians from November 2012 to March 2013. Physicians were contacted through existing medical and health care organizations, which were asked to distribute the survey to their members. Direct email invitations to physician members were sent by five organizations, and links from organization websites to the survey were provided by three organizations. Electronic invitations included a summary of the survey, consent information and a link to access the online survey.

Survey questions were adapted from prior needs assessment surveys distributed by the Canadian Consortium for the Investigation of Cannabinoids (CCIC) between 2009 and 2012 [4]. The research team reviewed the survey for construct validity and four physicians (a rheumatologist, anesthesiologist, internist, and pain specialist) pilottested the survey. Limesurvey (https://www.limesurvey. $\mathrm{org} / \mathrm{en} /$ ) was selected to host the survey as it is supported by McGill University and data are securely stored within the institution. The study protocol was approved by the McGill University Health Centre Research Institute Research Ethics Board.

The survey consisted of six sections. The first section concerned knowledge factors - respondents were asked to rank their perceived current and desired level of knowledge on 9 CTP-related topics (see Table 1) using a 5 -point Likert scale (1: very poor; 5 : very good). They were also asked to rank how strongly they felt the need for education on CTP using a 5-point Likert scale (1: not at all; 5 very strongly). The second section addressed experience - five questions with binary responses (yes or no) explored physicians' clinical experiences with pharmaceutical cannabinoids, the federal MMAR process and discussions regarding CTP with their patients. The third section addressed barriers - a list of potential barriers regarding the use of CTP were offered, from which the respondents could select one or more, as well as the opportunity to indicate any other obstacles to the use of CTP in their practice. The fourth section concerned attitudes - respondents were asked to specify which health care professionals, if any, they felt should be authorized to approve CTP for patient use. They were also asked to rank, using a 5-point Likert scale (1: strongly agree; 5: strongly disagree), how strongly they agreed with a series of statements about personal comfort levels with prescribing or authorizing CTP. The fifth section addressed educational approaches - eleven commonly used educational methods were listed from which respondents were asked to select their preferences, along with an opportunity to provide other alternatives or comments. Finally, the sixth section requested demographic information - respondents were asked to indicate region, setting and focus of their practice, and number of years in practice. The survey took an estimated 10-15 minutes to complete.

\section{Data analysis}

Descriptive statistics (frequencies and percentages) were used to summarize respondents' knowledge, experiences, barriers, attitudes, preferred educational approaches, and demographic information. Open-ended comments were reviewed for common themes, sorted and counted. Data were entered and analysed using Microsoft Excel ${ }^{\bullet}$ (Redmond, USA).

The difference between current and desired knowledge levels was used to determine a perceived knowledge gap. The knowledge gap was calculated based on how much greater the individual, not average, desired knowledge level was compared to their current knowledge level. Only response pairs were used for the calculation; responses only to the current or desired question were excluded, and responses where the indicated desired level was lower than the current level were also excluded.

\section{Results}

\section{Participant demographics}

Eight of 15 organizations contacted agreed to distribute the survey to their members or to post the survey on their websites. Participating organizations were the Canadian Association for HIV Research, the Canadian HIV Trials Network, the University of British Columbia Faculty of Medicine Office of Continuing Medical Education, the Canadian Association for Physical Medicine and Rehabilitation, the Canadian Consortium for the Investigation of 
Table 1 Analysis of knowledge scores and gaps for therapeutic use of cannabis (ranked by gap size)

\begin{tabular}{|c|c|c|c|}
\hline Knowledge area & $\begin{array}{l}\text { Mean current knowledge } \\
\text { score (1-5) }\end{array}$ & $\begin{array}{l}\text { Mean desired knowledge } \\
\text { score }(1-5)\end{array}$ & Mean GAP ${ }^{1}$ \\
\hline $\begin{array}{l}\text { Dosing and creating effective treatment plans for patients using } \\
\text { medical cannabis }\end{array}$ & 2.25 & 3.95 & 1.78 \\
\hline $\begin{array}{l}\text { Similarities and differences between dried cannabis, other forms } \\
\text { of cannabis products, and prescription cannabinoid medications }\end{array}$ & 2.36 & 4.00 & 1.70 \\
\hline Health Canada's Marihuana Medical Access Regulations (MMAR) Program & 2.43 & 3.99 & 1.60 \\
\hline Laws and regulations surrounding the medical use of cannabis & 2.65 & 4.11 & 1.49 \\
\hline Safety, warning signs and precautions for patients using medical cannabis & 2.84 & 4.21 & 1.48 \\
\hline Alternative routes of administration of medical cannabis & 2.72 & 4.02 & 1.42 \\
\hline Mechanism of action of cannabis (endocannabinoid system) & 2.78 & 4.06 & 1.39 \\
\hline Potential risks of using cannabis for medical purposes & 3.06 & 4.23 & 1.28 \\
\hline Potential therapeutic uses for cannabis & 3.07 & 4.17 & 1.22 \\
\hline
\end{tabular}

${ }^{1}$ Gap is calculated (using individual response pairs) $=$ (desired knowledge level -current knowledge level).

Cannabinoids, the McGill University Continuing Professional Development Office, MedCanAccess, and RxMedia Healthcare Communications Inc. Based on the estimated size of organisational mailing lists and organisation member outreach, we estimated that a total of 25,298 invitations to participate were sent. The survey was accessed a total of 580 times. From the total number of times accessed, 108 did not proceed past the introduction and consent page, 19 viewed the survey but did not provide any responses, and 27 did not submit their responses. A total of 426 usable and complete responses were received.

Demographic characteristics of respondents are presented in Table 2. Just over half of the respondents (54\%) were physicians with 21 years or more in practice. While we do not have national data on the distribution of physicians by years of practice, $42 \%$ of physicians are over the age of $55 y$ in Canada, and $68.1 \%$ are over $45 y$, suggesting that our sample is roughly consistent with national physician demographics [11]. The survey was completed in English by $91 \%$ and in French by $9 \%$ of respondents. Respondents' region and setting of practice were roughly proportional to the Canadian national physician distribution [12].

\section{Knowledge}

The perceived current and desired knowledge levels on 9 CTP related sub-topics are shown in Table 1 . The lowest average current knowledge levels were found for dosing and creating effective treatment plans for patients using CTP (2.25/5) and similarities and differences between dried cannabis, other forms of cannabis products, and prescription cannabinoid medications (2.36/5). The highest average desired knowledge levels concerned potential risks of using CTP (4.23/5) and safety, warning signs and precautions for patients using CTP (4.21/5); for these topics, $87.5 \%$ and $87.3 \%$ of respondents desired a good or very good level of knowledge respectively. The largest gap between perceived current and desired knowledge levels was identified for dosing and the development of treatment plans (average gap $=1.78$ ) followed by comparison of cannabis, cannabis products and prescription cannabinoids (average gap $=1.70$ ) and knowledge of the regulatory framework (average gap $=1.60$ ). The need for education on cannabis in medicine was reported as strong or very strong by $64 \%$ of respondents, compared to $19 \%$ who were neutral, and $17 \%$ not very strongly or not at all.

\section{Experiences}

Most respondents (79\%) reported having been approached by a patient and/or his/her family to discuss the use of CTP, while $39 \%$ reported initiating a discussion with a patient and/or his/her family on the use of CTP. Two-thirds of respondents (66\%) reported having patients using CTP, while 36\% reported having ever signed a medical declaration for the MMAR. Experiences with pharmaceutical cannabinoid medications were varied. Of the $59 \%$ who had ever prescribed a cannabinoid, nabilone was the most common (51\%), followed by dronabinol (19\%) and nabiximols (18\%), while $41 \%$ of respondents reported having never prescribed a pharmaceutical cannabinoid.

\section{Barriers}

The list of barriers to the use of CTP are shown in Table 3. The most common was a concern that patients who request CTP may actually want it for recreational purposes (65\%), while a lack of guidelines for the clinical use of cannabis and the need for more data on risks and benefits were reported by $64 \%$ and $56 \%$ of respondents, respectively. 
Table 2 Demographic characteristics of needs assessment respondents $(n=426)$

\begin{tabular}{|c|c|c|}
\hline Characteristic & $\mathbf{n}$ & $\%$ \\
\hline \multicolumn{3}{|l|}{ Area of practice } \\
\hline GP/FP & 117 & 27 \\
\hline GP/FP with enhanced area & 72 & 17 \\
\hline Specialist & 219 & 51 \\
\hline Other ${ }^{1}$ : & 6 & 1 \\
\hline Not specified & 12 & 3 \\
\hline \multicolumn{3}{|l|}{ Number of years in practice } \\
\hline 0 to 5 & 40 & 9 \\
\hline 6 to 10 & 39 & 9 \\
\hline 11 to 15 & 45 & 11 \\
\hline 16 to 20 & 59 & 14 \\
\hline 21 or more & 230 & 54 \\
\hline Not specified & 13 & 3 \\
\hline \multicolumn{3}{|l|}{ Region of practice } \\
\hline Atlantic & 38 & 9 \\
\hline Quebec & 100 & 23 \\
\hline Ontario & 128 & 30 \\
\hline Prairies & 70 & 16 \\
\hline $\mathrm{BC}$ & 64 & 15 \\
\hline Territories & 6 & 1 \\
\hline Not specified & 20 & 5 \\
\hline \multicolumn{3}{|c|}{ Community where practicing } \\
\hline Urban & 226 & 53 \\
\hline Rural & 92 & 22 \\
\hline Both & 96 & 23 \\
\hline Not specified & 12 & 3 \\
\hline \multicolumn{3}{|c|}{ Language of survey completion } \\
\hline English & 388 & 91 \\
\hline French & 38 & 9 \\
\hline
\end{tabular}

${ }^{1}$ Resident (2), Medical Advisor (2), Not Specified (2).

\section{Attitudes}

When asked which health care professionals should be authorized to approve CTP, 85\% reported that specialist physicians and $74 \%$ reported that family physicians should have this authority. Respondents were divided regarding nurse practitioners; $25 \%$ of respondents believed that they should and $60 \%$ believed they should not be authorized to approve CTP. The majority of respondents believed that other health care professionals should not be authorized to approve CTP (Table 4).

Seventy-one percent of respondents reported that they would feel more comfortable discussing CTP with patients/patient family members if they had more education about it, and $70 \%$ felt that with more education they would be better able to treat patients using cannabis.
Comfort level with CTP was also influenced by liability protection (62\%) or the availability of specific training for physicians to participate in the program (61\%) (Table 5).

\section{Educational approaches}

The preferred formats for receiving educational information were peer-reviewed literature reviews on specific topics (55\%), online learning programs as part of continuing medical education (54\%), online resources (46\%), workshops/small-group learning sessions (45\%) and symposia/conferences (44\%) (Table 6).

\section{Discussion}

There is a clear need for education for health care professionals on the use of CTP. We report the results of a national survey of Canadian physicians' perceived knowledge gaps and perceived needs concerning CTP. We found that the largest gaps between current and desired knowledge concerned dosing, the development of treatment plans, and comparisons between cannabis and existing prescription cannabinoids. There was an expressed need for better knowledge of the risks and benefits of CTP. Respondents thought that both specialists and family physicians were capable of authorising CTP; however, overall it was felt that pharmacists or naturopathic doctors should not have this authority. Concerns regarding the recreational use of cannabis masquerading as medical use was common among respondents. Respondents reported that their comfort level in including CTP in their practice would increase with additional education, and reported their educational needs would be best met with focused literature reviews, online, and small group continuing medical education activities.

Ranking perceived knowledge levels on several related topics allows a comparison of 'what is' and 'what should be' regarding perceived educational needs, and enables the quantification of perceived knowledge gaps. Describing and ranking the perceived knowledge gaps for several CTP subtopics enables a comparison of gaps between topics, and enables the identification of strategies to reduce the gaps $[13,14]$. Based on our data, Canadian physicians perceive their current knowledge level on CTP to be low, while desiring a high knowledge level, consistent with other reports that physicians desire education on CTP $[9,10]$. More specifically, we identified the lowest perceived knowledge levels, and largest knowledge gaps, to be regarding hands-on clinically relevant CTP subtopics, including; dosing and treatment plans, comparing between cannabinoids, and Canadian CTP regulations. In contrast, we identified higher perceived current knowledge levels, and smaller knowledge gaps, to be regarding more theorybased CTP subtopics, including; the mechanism of action of cannabis, potential risks, and potential benefits. This suggests that practical hands-on style information should be prioritized. 
Table 3 Perceived barriers regarding the use of CTP

\begin{tabular}{|c|c|c|}
\hline Factor & $\mathrm{n}^{1}$ & $\%$ \\
\hline Concern that patients who request medical cannabis may actually want it for recreational purposes & 279 & 65 \\
\hline Lack of clinical guidelines for the use of cannabis for medical purposes & 271 & 64 \\
\hline Risks and benefits are not sufficiently clear for potential therapeutic uses & 237 & 56 \\
\hline Lack of personal knowledge/education or information regarding the use of cannabis for medical purposes & 214 & 50 \\
\hline Insufficient information regarding the appropriate use of cannabis for medical purposes & 212 & 50 \\
\hline $\begin{array}{l}\text { Instruction from medical associations, licensing bodies, Royal College, College of Family Physicians or Canadian } \\
\text { Medical Protective Association }\end{array}$ & 201 & 47 \\
\hline Potential liability concerns & 194 & 46 \\
\hline Concern about possible side effects & 190 & 45 \\
\hline Uncertainty about possible interactions with other medications & 167 & 39 \\
\hline Belief that cannabis is not an appropriate treatment in a specific case & 141 & 33 \\
\hline $\begin{array}{l}\text { Requirement to sign a declaration indicating awareness that cannabis is not an approved therapeutic under the } \\
\text { Food and Drug Regulations }\end{array}$ & 138 & 32 \\
\hline Uncertainty over whether cannabis has any medicinal value & 117 & 27 \\
\hline Availability of prescription cannabinoids (e.g. nabiximols, dronabinol or nabilone) & 98 & 23 \\
\hline Other & 66 & 15 \\
\hline
\end{tabular}

${ }^{1}$ Subjects may choose more than one response.

Two interesting discrepancies emerge from responses about experiences with the clinical use of CTP. Firstly, patients initiate most of the discussions about CTP, and physicians feel they have insufficient information and lack guidance on the topic. Few guidelines exist for CTP $[15,16]$, while Canadian physicians have reported that clinical practice guidelines would be useful or very useful [3]. Secondly, only one third of respondents had signed a patient's application to possess CTP through the federally regulated program, yet two thirds reported having patients using CTP. It is possible that respondents had patients who had received CTP from another physician. The discrepancy between the prevalence of self reported use of CTP (48\%) and the proportion of patients with

Table 4 Beliefs about which health care professionals should have authority to approve/prescribe CTP

\begin{tabular}{|c|c|c|c|c|}
\hline \multirow[t]{2}{*}{ Health care professional } & \multicolumn{2}{|l|}{ Yes } & \multicolumn{2}{|l|}{ No } \\
\hline & $\mathrm{N}$ & $\%^{1}$ & $\mathbf{N}$ & $\%$ \\
\hline Specialist physicians & 363 & 85 & 42 & 10 \\
\hline Primary care physicians/family physicians & 316 & 74 & 94 & 22 \\
\hline Nurse practitioners & 108 & 25 & 256 & 60 \\
\hline Pharmacists & 67 & 16 & 285 & 67 \\
\hline Naturopathic doctors & 60 & 14 & 293 & 69 \\
\hline Traditional Chinese medicine practitioners & 49 & 12 & 303 & 71 \\
\hline Nurses & 28 & 7 & 321 & 75 \\
\hline
\end{tabular}

${ }^{1}$ Percentages may not add up to $100 \%$ as missing data or non-responses are not included. legal access through Canada's federal program (32\%) has been reported previously in certain populations $[17,18]$.

The highest reported obstacle to CTP was found to be a concern that patients are actually seeking cannabis for recreational purposes, supporting similar results from previous reports $[4,9,10]$. Patients report experiencing a lack of trust by health care providers, and suggest that it is due to the stigma associated with cannabis as an illegal recreational drug [17]. Such views may be a result of the blurred lines between therapeutic and recreational use reported in the media [19]. Another potential cause for this distrust of patient motivation for CTP use stems from the fact that some of the patient populations in which cannabis may be a potential therapeutic option, such as chronic pain, HIV/AIDS, and mental health issues, are already stigmatized [17]. Canadian patients using CTP have reported the stigma associated with cannabis negatively impacts their relationship with health care providers, creating a barrier to receiving the health care they need, and increased levels of physician education may be a means to decrease the stigma [17]. It may be the case that negative attitudes and values about cannabis in general influence potential therapeutic uses, as has been reported in other controversial therapeutic areas like methadone maintenance therapy [20]. Finally, the demographic overlap (young white males) between medical cannabis users and recreational users also adds to the potential for physician mistrust of the real medical 'necessity' for CTP [21,22].

Our survey has several potential limitations. The low number of responses creates a potential selection bias, which affects our ability to generalize findings, and 
Table 5 Factors influencing comfort level of the clinical use of cannabis for therapeutic purposes

\begin{tabular}{|c|c|c|c|c|c|c|}
\hline \multirow[t]{2}{*}{ Factor } & \multicolumn{2}{|c|}{ Agree* } & \multicolumn{2}{|c|}{ Neutral } & \multicolumn{2}{|c|}{ Disagree } \\
\hline & $\mathrm{N}$ & $\%$ & $\bar{N}$ & $\%$ & $\bar{N}$ & $\%$ \\
\hline $\begin{array}{l}\text { I would feel more comfortable discussing the medical use of cannabis with patients/patient family members if } \\
\text { I had more education about it }\end{array}$ & 304 & 71 & 56 & 13 & 54 & 13 \\
\hline I feel that with more education I would be better able to treat patients using medical cannabis & 300 & 70 & 57 & 13 & 56 & 13 \\
\hline I would feel more comfortable authorizing medical cannabis if Health Canada offered me protection from liability & 265 & 62 & 87 & 20 & 60 & 14 \\
\hline $\begin{array}{l}\text { I would feel more comfortable if physicians who participated in access to CTP were required to undergo a specific } \\
\text { training or licensing program }\end{array}$ & 259 & 61 & 81 & 19 & 74 & 17 \\
\hline
\end{tabular}

Percentages may not add up to $100 \%$ as missing data or non-responses are not included.

*Likert scale responses were collapsed to dichotomous outcomes: agree (strongly agree and agree) and disagree (strongly disagree and disagree).

which may not be representative of Canadian physicians overall. A true response rate is impossible to calculate, as the denominator is unknown; we do not know how many different physicians received or saw the survey. The low number of overall responses may be due, in part, to the lack of monetary compensation for participation [23], a large number of similar requests, lack of time, or hesitancy to enter answers into a survey on this topic. Another contributing factor to the low number of responses may be the source of the invitations; other non-medical-college distributed surveys have reported similarly low response rates from Canadian physicians [24], whereas surveys sent by provincial or national medical colleges or associations have reported response rates around $20 \%$ or higher $[9,10,20,25]$. An additional limitation is that a number of recipients of email invitations were based on lists of previous participants in CTP-related continuing medical education programs, or those who had expressed interest in topic of CTP to a variety of sources. This may have selected participants with specific interest in CTP or who had already had some education on this topic. However the number of responses received is similar to other recent physician surveys on CTP including the 607 responses received by the

\section{Table 6 Preferred formats of educational information}

\begin{tabular}{lll}
\hline Format & $\mathbf{n}^{\mathbf{1}}$ & $\mathbf{\%}$ \\
\hline Peer-reviewed literature reviews on specific topics & 236 & 55 \\
On-line learning programs as part of continuing & 230 & 54 \\
medical education & & \\
On-line resources & 195 & 46 \\
Workshops/small-group learning sessions & 192 & 45 \\
Symposia/conferences & 188 & 44 \\
A monograph on cannabis (similar to a drug product monograph & 169 & 40 \\
Expert speaker tour & 149 & 35 \\
Grand rounds & 141 & 33 \\
Topic-specific reports & 97 & 23 \\
Mentorship/preceptorship program & 79 & 19 \\
Newsletter & 63 & 15 \\
Other & 39 & 9 \\
\hline
\end{tabular}

${ }^{1}$ Subjects may choose more than one response.
Canadian Medical Association (CMA) [10], and 520 responses to the Colorado physician survey [9]. Finally, this study is limited by the focus on perceived needs and did not include an assessment of unperceived needs; we did not determine whether high levels of perceived knowledge were in fact truly high levels of knowledge based on external evaluation. Triangulating perceived needs with unperceived needs should be the focus of further research.

Our results support the need for further medical education and training on CTP [9]. In alignment with expressed needs for more information on CTP, physicians reported that focused peer-reviewed summaries on specific CTP sub-topics would be helpful in enhancing their knowledge on this area. The preference for online education is consistent with trends towards e-learning in the health professions [26]. Additionally, studies have reported that educational interventions that enhance competencies and skills have a direct influence on improvement of patient outcomes [27].

\section{Conclusions}

Cannabis is not a pharmaceutical product and thus has not taken a traditional route into the physicians' toolbox of potential therapies and has not undergone the same rigorous testing demanded by Health Canada of pharmaceutical medications. However, research on cannabinoids and the endocannabinoid system has increased over the past 20 years. This growing body of research needs to be translated into resources to address physicians' professional knowledge and practice gaps to enable them to make more informed decisions about CTP. The new MMPR allows nurse practitioners and physicians to authorize patients' legal access to CTP. The knowledge gaps and educational needs among nurse practitioners is yet to be described. Future needs assessments among physicians and nurse practitioners should evaluate unperceived needs in addition to perceived needs. The transition to the new federal regulations provides an opportunity to develop and implement evidence-based education for physicians and nurse practitioners that should address the existing perceived knowledge gaps we describe, and to evaluate the effectiveness of such strategies on clinical practice and, ultimately, on health outcomes. 


\section{Competing interests}

DZ and MW are employed by the Canadian Consortium for the Investigation of Cannabinoids, a non profit organization that designs, develops and delivers accredited cannabinoid education programs. All other authors declare that they have no competing interests.

\section{Authors' contributions}

DZ designed the study, developed the data collection instrument, collected and analysed the data. RC contributed to the survey design and methodology. RT contributed to survey design and data analysis. AL and FL contributed to survey design, data collection, analysis and interpretation. MW conceived of the study, and contributed to survey design, data collection, analysis and interpretation. All authors read and approved the final manuscript.

\section{Acknowledgements}

We would like to acknowledge the Canadian Association for Physical Medicine and Rehabilitation, the Canadian Consortium for the Investigation of Cannabinoids, McGill University Office of Continuing Health Professional Education, MedCanAccess, and RxMedia Healthcare Communications Inc. for sending direct email invitations to their Canadian physician members and contacts. We would also like to acknowledge the Canadian Association for HIV Research, the Canadian HIV Trials Network, the University of British Columbia Faculty of Medicine Office of Continuing Medical Education for including an invitation and link to participate in this survey on their website. We would like to acknowledge the feedback received regarding the initial survey design from Chloe Wu, MSc, MEd, Continuing Professional Development, Faculty of Medicine, University of British Columbia. Partial funding for this study was received in the form of unrestricted educational grants from Santé Veritas Therapeutics, Bedrocan BV, and Prairie Plant Systems Inc

\begin{abstract}
Author details
${ }^{1}$ Alan Edwards Pain Management Unit, McGill University Health Center Research Institute; Canadian Consortium for the Investigation of Cannabinoids, A5.140 Montreal General Hospital, 1650 Cedar Avenue, Montreal, Quebec H3G 1A4, Canada. ${ }^{2}$ Interdisciplinary Studies Graduate Program, University of British Columbia, Vancouver, Canada. ${ }^{3}$ Département des sciences de la santé, Université du Québec en Abitibi-Témiscamingue, Québec, Canada. ${ }^{4}$ Continuing Health Professional Education, Faculty of Medicine, McGill University, Montreal, Québec, Canada. ${ }^{5}$ Community Programs, Urban Care Health Group, Toronto, Ontario, Canada.
\end{abstract}

Received: 29 June 2014 Accepted: 5 March 2015

Published online: 19 March 2015

\section{References}

1. Marihuana for Medical Purposes Regulations: Regulatory impact analysis statement. Canada Gazette; 2012. http://gazette.gc.ca/rp-pr/p1/2012/201212-15/html/reg4-eng.html]

2. Marihuana for Medical Purposes Regulations. Canada Gazette; 2013. http://gazette.gc.ca/rp-pr/p1/2012/2012-12-15/html/reg4-eng.htm

3. CMA. CMA Survey Results Point to MD Concern over Medical Marijuana. CMAJ. 2012:184:1860

4. Ziemianski D, Tekanoff R, Luconi F, Ware M. Cannabinoids in clinical practice: experiences and educational needs. In: Proceeds of the Canadian Pain Society 2012. Pain Research and Management 2012;17(3):229.

5. Linn LS, Yager J, Leake B. Physicians' attitudes toward the legalization of marijuana use. West J Med. 1989;150:714-7.

6. Doblin RE, Kleiman MA. Marijuana as antiemetic medicine: a survey of oncologists' experiences and attitudes. J Clin Oncol. 1991;9:1314-9.

7. Schwartz RH, Voth EA, Sheridan MJ. Marijuana to prevent nausea and vomiting in cancer patients: a survey of clinical oncologists. South Med J. 1997;90:167-72.

8. Charuvastra A, Friedmann PD, Stein MD. Physician attitudes regarding the prescription of medical marijuana. J Addict Dis. 2005;24:87-93.

9. Kondrad E, Reid A. Colorado family physicians' attitudes toward medical marijuana. J Am Board Fam Med. 2013;26:52-60.

10. Canadian Mediical Association. Our members' views on medicinal marijuana. 2012. [https://www.cma.ca/En/Pages/survey-summary-june2012.aspx]

11. National Physician Survey [http://nationalphysiciansurvey.ca/wp-content/ uploads/2014/11/2014-National-EN.pdf]
12. Canadian Medical Association. Number of physicians by province/territory and specialty, Canada, 2014. In CMA Masterfile: CMA; 2014 [https://www. cma.ca/Assets/assets-library/document/en/advocacy/01-physicians-bySpecialty-Province-2014-e.pdf\#search=Number\%20of\%20physicians\%20by\% 20specialty\%20and\%20age\%2C\%20Canada\%2C\%202014]

13. Moore DE, Green JS, Gallis HA. Achieving Desired Results and Improved Outcomes: Integrating Planning and Assessment Throughout Learning Activities. J Contin Educ Health Prof. 2009;29:1-15.

14. Fox RD. Revisiting "Discrepancy Analysis in Continuing Medical Education: A Conceptual Model". J Contin Educ Health Prof. 2011;31:71-6.

15. Grant I, Atkinson JH, Gouaux B, Wilsey B. Medical marijuana: clearing away the smoke. Open Neurol J. 2012;6:18-25.

16. Clark AJ, Lynch ME, Ware M, Beaulieu P, McGilveray IJ, Gourlay D. Guidelines for the use of cannabinoid compounds in chronic pain. Pain Res Manag. 2005;10(Suppl A):44A-6.

17. Bottorff JL, Bissell LJ, Balneaves LG, Oliffe JL, Capler NR, Buxton J. Perceptions of cannabis as a stigmatized medicine: a qualitative descriptive study. Harm Reduct J. 2013;10:2.

18. Walsh Z, Callaway R, Belle-Isle L, Capler R, Kay R, Lucas P, et al. Cannabis for therapeutic purposes: patient characteristics, access, and reasons for use. Int J Drug Policy. 2013;24:511-6.

19. Parloff R. How pot became legal. Fortune. 2009;160:140-2. 144, 146.

20. Dooley J, Asbridge M, Fraser J, Kirkland S. Physicians' attitudes towards office-based delivery of methadone maintenance therapy: results from a cross-sectional survey of Nova Scotia primary-care physicians. Harm Reduct J. 2012;9:20.

21. Ware MA, Doyle CR, Woods R, Lynch ME, Clark AJ. Cannabis use for chronic non-cancer pain: results of a prospective survey. Pain. 2003;102:211-6.

22. Clark AJ, Ware MA, Yazer E, Murray TJ, Lynch ME. Patterns of cannabis use among patients with multiple sclerosis. Neurology. 2004;62:2098-100.

23. Church $\mathrm{AH}$. Estimating the effect of incentives on mail survey response rates: a meta-analysis. Public Opinion Quarterly. 1993;57:62-79.

24. Lebrun CM, Mrazik M, Prasad AS, Tjarks BJ, Dorman JC, Bergeron MF, et al. Sport concussion knowledge base, clinical practises and needs for continuing medical education: a survey of family physicians and cross-border comparison. Br J Sports Med. 2013;47:54-9.

25. Toguri $C$, Jong $M$, Roger J. Needs of specialists in rural and remote Canada. Can J Rural Med. 2012;17:56-62.

26. Waldrop MM. Online learning: Campus 2.0. Nature. 2013;495:160-3.

27. Bellamy N, Goldstein LD, Tekanoff RA. Continuing medical education-driven skills acquisition and impact on improved patient outcomes in family practice setting. J Contin Educ Health Prof. 2000;20:52-61.

\section{Submit your next manuscript to BioMed Central and take full advantage of:}

- Convenient online submission

- Thorough peer review

- No space constraints or color figure charges

- Immediate publication on acceptance

- Inclusion in PubMed, CAS, Scopus and Google Scholar

- Research which is freely available for redistribution

Submit your manuscript at www.biomedcentral.com/submit
C Biomed Central 